\title{
Study the Best practices in T\&M (Time and Material) employee engagement model and recommend possible interventions in WI-IMS (Wipro InfoTech- Infrastructure Management Services)
}

\author{
Akshay Grover ${ }^{1}$, Kalpana Jayakrishnan ${ }^{2, *}$ \\ ${ }^{1}$ MBA final year Marketing and HR student, Acharya Institute of Management and Sciences, Bangalore \\ ${ }^{2}$ Program Manager, HR Department, Bangalore University, India
}

Email address:

Groverakshay27@yahoo.com (A. Grover),kalpijay@gmail.com (K. Jayakrishnan)

\section{To cite this article:}

Akshay Grover, Kalpana Jayakrishnan. Study the Best Practices in T\&M (Time and Material) Employee Engagement Model and Recommend possible Interventions in WI-IMS (Wipro InfoTech- Infrastructure Management Services). Journal of Human Resource Management. Vol. 2, No. 1, 2014, pp. 16-21. doi: 10.11648/j.jhrm.20140201.13

\begin{abstract}
It is essential for an organization to sustain in the long run have an engaged workforce. An engaged workforce takes an organization to great heights. Engaged employees contribute to the bottom line. Employees feel engaged when they find personal meaning and motivation in their work, receive positive interpersonal support, and operate in an efficient work environment. An employee when engaged emotionally, cognitively and physically helps creating a great place to work. The engagement levels in the organization determine the enthusiasm of an employee to come to the work every single day. The more engaged the employee is, more is the likelihood of the organization to be a great place to work. Engagement is linked to three essential forces in the organization - Attrition, Productivity \& Profitability. That essentially is the reason that today, all efforts are being made to make the employees feel that the organization cares for him and wants his success and growth. This organization is no different and thus wanted to understand ways of creating employee delight for its employees. Taking the employee satisfaction survey as the base, the problem areas were identified and accordingly, the recommendations to address the problems were given.
\end{abstract}

Keywords: Employee Engagement, Retention, Major Challenge

\section{Introduction}

A major challenge for HR today is how to engage and ultimately retain employees particularly amid an economic downturn. It is no longer sufficient to carry out daily routine processes for the functioning of the organization. HR management today involves many of the subjective and ambiguous concepts like employee engagement. The purists might even frown at the scope and the vagueness of the topic like engagement.

Employee engagement is a desirable condition, has an organizational purpose, and connotes involvement, commitment, passion, enthusiasm, focused effort, and energy, so it has both attitudinal and behavioral components. A number of popular views of engagement suggest that engaged employees not only contribute more but also are more loyal and therefore less likely to voluntarily leave the organization.
An amalgamation of commitment, loyalty, productivity and ownership is also perceived to be a way of measuring engagement. The categories of job satisfaction, organizational commitment, psychological empowerment and job involvement form another school of thought. Resource availability, opportunity for development and clarity of expectations is the Gallup way of looking at employee satisfaction facets.

Engagement is above and beyond simple satisfaction with the employment, arrangement or basic loyalty to the employer-characteristics that most companies have measured for many years. Engagement, in contrast, is about passion and commitment - the willingness to invest oneself and expend one's discretionary effort to help the employer succeed.

Satisfaction when assessed as feelings of energy, enthusiasm and positive affective states becomes a facet of engagement. Organization commitment is an important 
facet of the state of engagement as it is positive attachment to the larger organizational and measured as a willingness to exert energy in support of the organization, to feel proud as an organization member and have personal identification with the organization. Job involvement is looked at as an facet of psychological state of involvement. A feeling of empowerment connotes the inclination to action another state of engagement.

In a world that is changing in terms of the global nature of work and the aging of workforce, having engaged employees may be a key to competitive advantage.

The companies that get the state and behavioral employee engagement will have accomplished something that other competitors would find difficult to imitate. It is very easy to change the price and product, it is another thing to create an engaged workforce.

\subsection{Statement of Problem}

It is not enough for HR today to perform its routine tasks. The rising importance of employee engagement across the spectrum of organizations has made them take notice and put it on their priority list. Employee engagement has been found to have a three-way effect on Attrition, Productivity and Profitability of an organisation. Thus it was nothing but imperative for this organization to take employee engagement to the next level where in came my project. The objective of my project was to study the best practices in T\&M Employee Engagement model and recommend possible interventions in WI-IMS. This included identifying employee engagement initiatives and keeping in place a control plan for its sustainability. The desired engagement spheres in employees are the psychological state engagement, behavioral state engagement and trait engagement. Simply put, an engaged employee is one who is emotionally, physically and cognitively attached to the organization. This further ensures the creation of a great place to work at. Employee engagement though being compelling on the surface, meaning of the concept is unclear. Hence my study involved firstly understanding the levers of employee engagement. This was done with the help of journals and a primary survey of a random sample of people.

This made me appreciate the expectations of workforce today, which was not restricted to remuneration alone. Once the parameters were identified, learning the best practices across the industries was the next logical step. This was carried out with the help of telephonic and in person interviews and administering online questionnaires. The findings were analyzed and the emerging trends across organizations were plotted.

Interacting with the business leaders and one- on-one interviews with them understood the feasibility of the recommendations. The understanding of organization structure and the business model led to the final list of recommendations, which would suit the firm. The major engagement themes that evolved at the end of the assignment are senior leadership and HR connect, organization culture, Learning and Development and career opportunities for growth. Transparent and regular organization updates and communication turned out to be a major engaging factor. Though remuneration is perceived to be a major engaging aspect, the study also revealed that compensation is not a major engaging factor.

\subsection{Time and Material (T\&M)}

The T\&M model works best for customers who want a flexible and agile project execution. Here they play a greater role in the development of the software product or solution. This model works best when requirements change frequently and is generally used for product development projects. In this model the customer carries virtually all the related risks of scope, quality of deliverables and project management. Therefore the margins for T\&M players are the lowest. There are no risks and no investments by service providers. The service provider assigns a team to the customer and the actual time spent by the team on the project is billed. Monthly invoicing is pro-rata, based on the total hours spent on the project and the rates for the skill sets involved. Traditionally, service providers are paid basis the number of person hours spent on writing code. So, to maximize their revenue, service providers try to maximize the hours spent and number of people used to write the code.

This model is suitable for clients who want to play a significant role in the project development process. As the model name suggest, the pricing is determined based the man-hours required to complete the project i.e. hourly charging. When the specification of project, scope of work and implementation of project plan cannot be effectively estimated during the initial phase, T \& M model is the best option to choose and proceed with the development.

The project involved designing a list of Employee Engagement Interventions. The parameters were zeroed on after the internal employee voices. The relationship between the engagement measures and business results were observed. The scope of the project included identifying suitable methods for the employee engagement initiatives for the establishment.
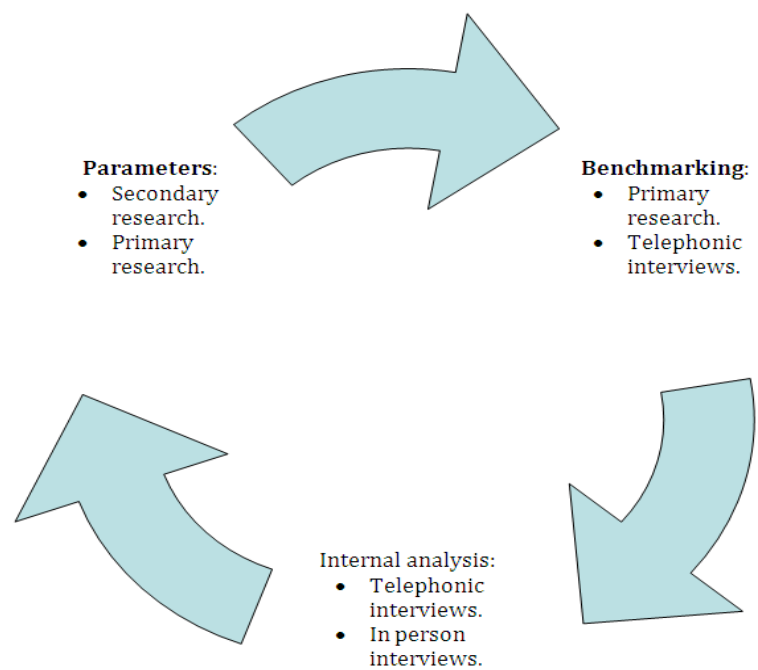

Figure 1: The above image explains the process followed to collect data. 


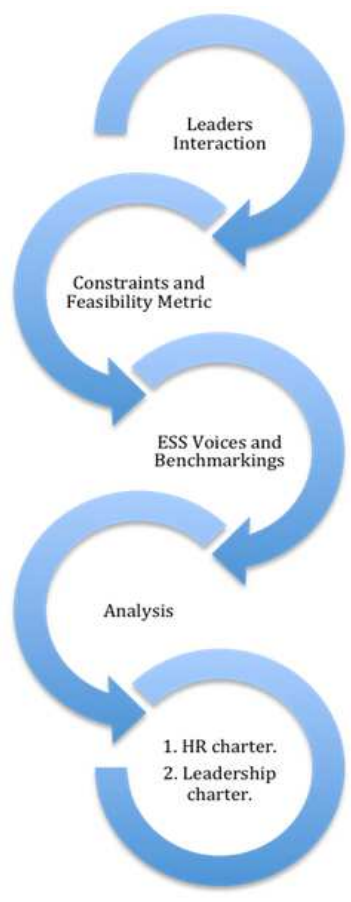

Figure 2: The above image explains process followed for the completion of the project.

\subsection{Employee Engagement Parameters}

Engaging the employees emotionally, cognitively and physically can ensure a Great Place to Work. Cognitive engagement refers to employees' beliefs about the company, its leaders and the workplace culture. The emotional aspect is how employees feel about the company, the leaders and their colleagues. The behavioral factor is the value-added component reflected in the amount of effort employees put into their work.

Ensuring a great place to work at is increasingly becoming important for companies all over because of the reasons of happier employees leading to better work productivity in turn leading to customer satisfaction. This in turn makes more and more profits certain for the institution. Retention of the employees and attracting best talent become the gradual result of putting into practice the engagement activities.

Companies need to give the three C's of engagements to employees. They being

- Connection

- Contribution

- Credibility

The employee needs in terms of the following should be capacitated:-

Basic needs: Clarity of work, materials and equipment Management Support: Encouragement, caring, supervision, recognition, person-job-fit

Teamwork: Best friend, co-workers, commitment to quality, and clarity of organizational purpose, value for one's opinion

Growth: Opportunity to learn, tangible progress

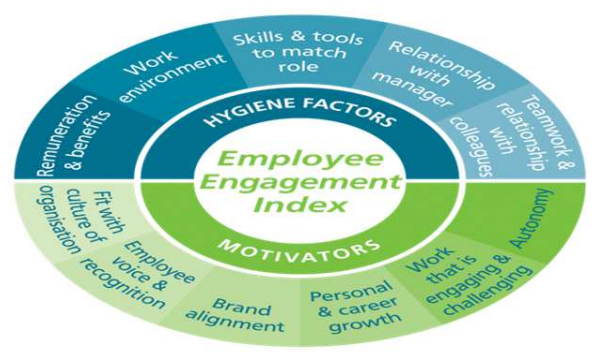

WeatherVANE

Figure 3: The above image depicts the Employee Engagement Index

The laundry list of best engagement practices that an organization can take up for its people is:

- $\quad$ Safe, Healthy And Happy Workplace

- Open Book Management Style

- $\quad$ Performance Linked Bonuses

- 360-Degree Performance Management Feedback System

- $\quad$ Fair Evaluation System For Employees

- Knowledge Sharing

- Highlight Performers

- Open House Discussions And Feedback Mechanisms

- Reward Ceremonies

- Delight Employees With The Unexpected

It is also to be borne in mind that there is no 'one size fits all' type of initiatives that can be implemented in organizations. It therefore becomes an organization's responsibility to encompass all kind of employees' namely:

- Mature workers

- Baby boomers

- Generation X

- Generation Y

This study has two components: Study based on Secondary data and study based on Primary Data.

\subsection{Secondary Research}

Mostly of papers and articles [as mentioned in the References section] were studied along with some online portals in order to understand the levers of employee engagement. Some organizations engagement policies were further referred to for the parameters formulation.

\section{Employee Engagement Parameters}

The primary and the secondary research led to the following key parameters of employee engagement. These parameters were found to be relevant to the organization and in sync with the company's parameters of engagement.

- Company's Leadership (strategy, policy, processes)

- Management of change.

- Communication

- Manager

- Growth \& Development (L\&D, rotational development opportunities, empowerment)

- Transparent Performance Management 
- Recognition and Rewards

- Compensation and Benefits

- Work Life Balance

- $\quad$ Recruitment \& On boarding experience

- Culture (work environment, policies, ergonomics, team members, inclusive environment)

In order to understand the best practices in terms of employee engagement across industries, external benchmarking was done. The objective of this study was to understand and evaluate the current position of engagement in the organization and discover areas and means of improvement. It was established that there were companies with good practices across sectors and thus a mix of best in class companies and the companies in the same league were researched. A total of 4 companies were researched. The best practices of these companies were captured telephonic interviews and online survey tools.

The research was carried out in the areas of:

- 'Fun at work' initiatives

- Infrastructure provided in terms of sports, canteen, recreation facilities etc

- Cross functional team meets in terms of Committees, Technical clubs and competitions

- $\quad$ HR connect

- $\quad$ Exit Interview Procedure

- Communication Channels in the organisation

- Work Life Balance

- Hipot engagement

- Mentorship Program

- Compensation and Benefits

- Rewards and Recognition

- Promotion Process

- Trainings

- Manager's Behavior

- Change Management

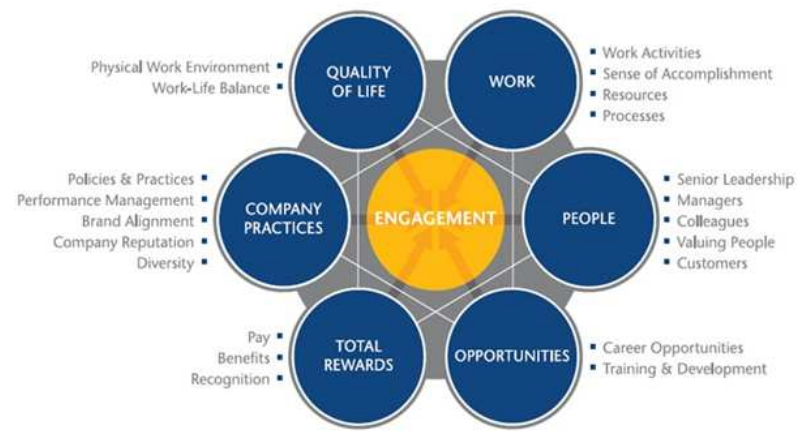

Figure 4: Model of the Employee Engagement Drivers

\subsection{Internal Benchmarking}

As the external benchmarking was being carried out, there was also an exercise of internal benchmarking that took place. Major tendencies that evolved across entities are as shown below in the figure. It was observed that the initiatives across organizations were in line with the external benchmarking analysis and trends. There were many similarities between the internal and external benchmarking findings that were discovered. This showed that there are many things that the organization as a whole was doing right, but at the entity level it was time to adopt the best practices across organizations and its own entities. Though many initiatives were quite common across organizations, there were some practices, which though not a popular choice stood out in the external benchmarking study conducted. Some of these initiatives though striking were very simple to implement and it was chosen to not overlook them. The 'out of the box' initiatives are also listed below, some of which were chosen to be implemented in the context of the subject organization.
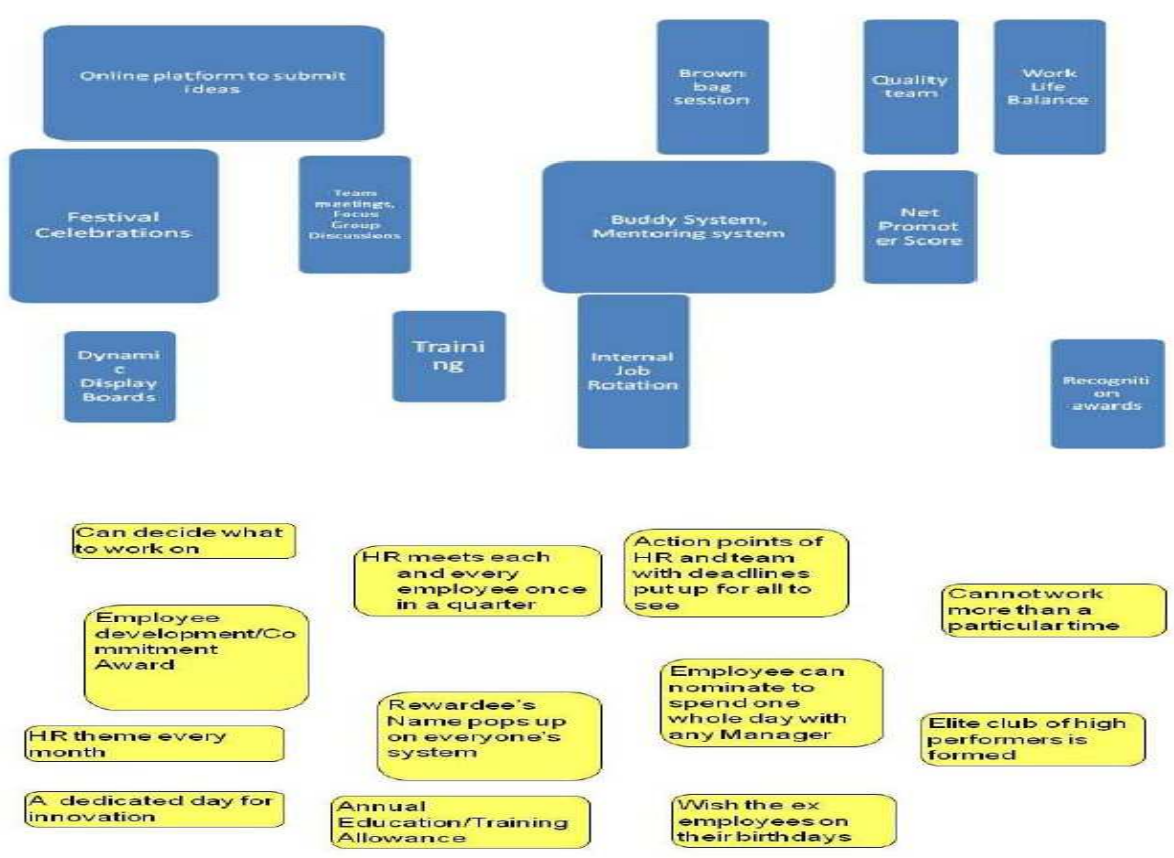

Figure 5: The image depicts the initiatives taken up by companies for Employee Retention. 
20 Akshay Grover and Kalpana Jayakrishnan: Study the Best Practices in T\&M (Time and Material) Employee Engagement Model and Recommend possible Interventions in WI-IMS (Wipro InfoTech- Infrastructure Management Services)

\subsection{Understanding the Business Model}

\subsubsection{Interaction with Business Leaders}

Understanding the business model was important for proposing any sort of employee engagement initiatives. Only if a fitment could be found between the organization culture and the proposals that were recommended, the interventions would be an accomplishment. After the initial analysis of external benchmarking, it was essential to appreciate the deep nuances of the business model prevalent. This could have been possible by discussing the proposed initiatives with the business leaders on an individual basis. One on one with leaders on common set of questions were set up in which a fair understanding of the constraints and challenges faced in terms of efforts, time and money were understood. The leaders were queried on the following list of questions in order to assess the feasibility of the initiatives proposed.

\subsection{Primary Research}

\subsubsection{Questionnaire for the Business Leaders}

1. What is the size of the T\&M team operating in your region?

2. Are there any issues relating to $\mathrm{T} \& \mathrm{M}$ Employee Engagement delivery model in your region?

3. What are the current issues, which you feel, are more prevalent in your region?

4. What are the issues that need to be addressed first according to you?

5. What according to you should be the possible interventions, which should be implemented in order to meet these challenges?

6. Are the problems which are prevailing in the organization are general or specific to T\&M Employee Engagement delivery model?

The primary focus of this interaction was to figure out the challenges, which WIPRO faced in different regions particularly in the T\&M Employee Engagement Model and subsequently Recommend Interventions to meet these challenges.

Different regions faced different problems and some of the problems were common. The results of the interactions were divided zone wise.

\subsection{Leadership Interaction Compilation General}

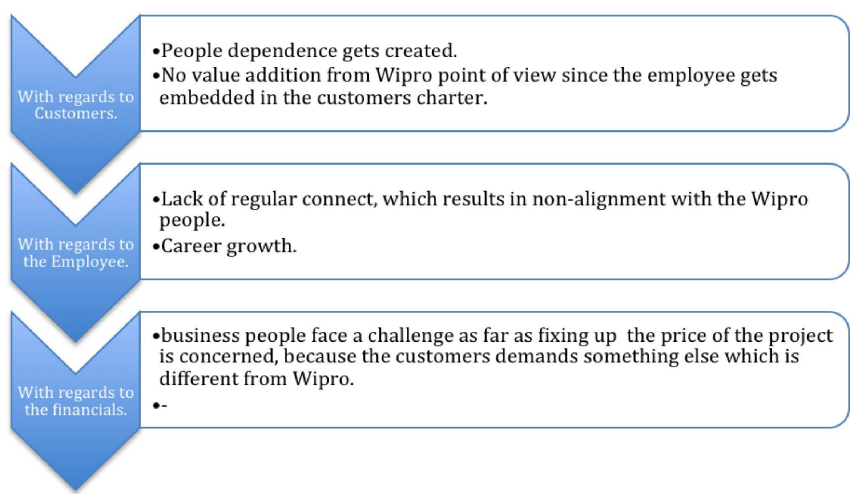

Figure 6
North

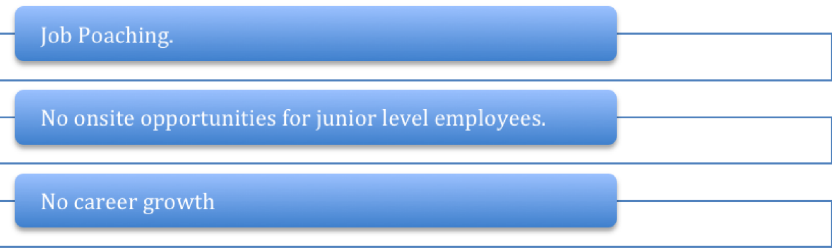

Figure 7

\section{South 1}

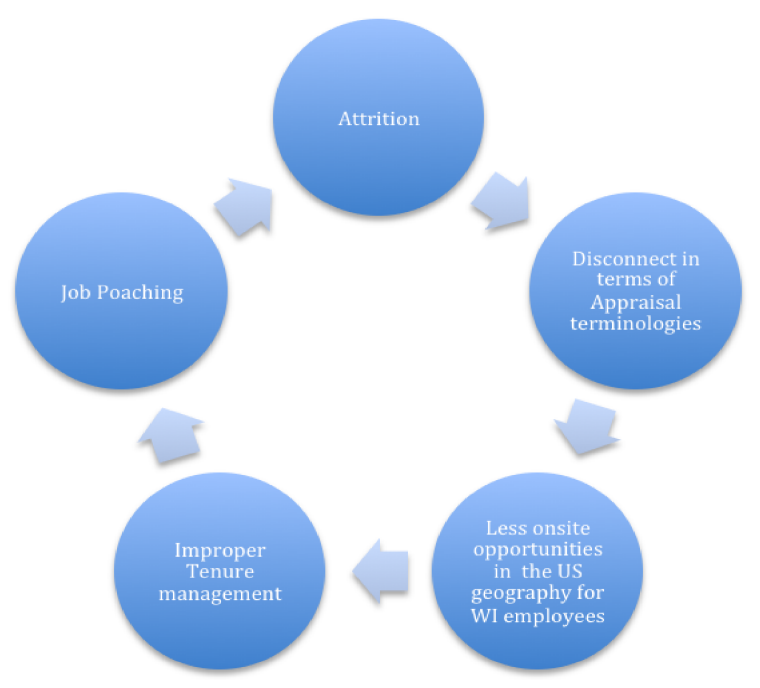

Figure 8

South 2

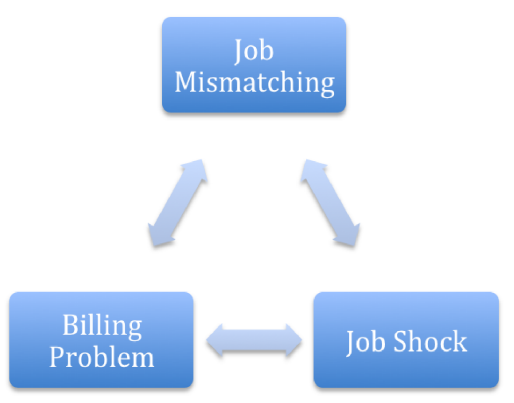

Figure 9

\section{South 3}

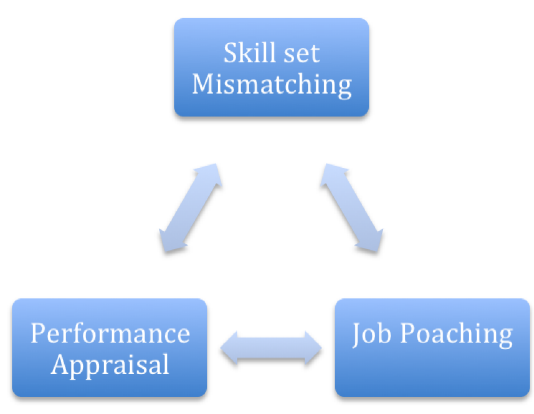

Figure 10 


\section{Recommendations}

\subsection{General Best HR Practices}

List of employee engagement initiatives that are generally carried out in a variety of organisations:

HR dashboard, Policy guru, The healthier yoga class, skip level meetings, HR business internship, exit interview analysis, spot awards, ideate to celebrate, Paanch Tantra, chill Wednesday, HR mail id, HR 1-0-1 connects, PSS, lets talk, committee stalls etc.

Recommendations for WI-IMS:

Rewards and Recognitions:

Endow

... Employee driven recognition program.

Category

Rewards and Recognitions

People Pleaser award

Employee who wishes to nominate another employee does so through an online portal, which is available at Wipro.

\section{Pinnacle Award Managers Choice Award}

Decision by BU council \& winners will be awarded at a ceremony.

- A reward and recognition program called "The success matrix", rewards employees on a monthly, quarterly and an annual basis, put up citations and awards on a "Wall of Fame".

- Flash of brilliance award: An award empowered upon an individual who has shown innovation in his work at the customer's workplace.

\section{People Connect}

1. Company's Internal magazine covering all happenings in your company.

2. Friday movie mania, indoor games and competition.

3. Koffee with "CEO".

\subsection{List of Deliverables}

As a part of the recommendations and control plan for the recommendations on the basis of the two-month study, the list of charters prepared is

1. External Benchmarking Report

2. HR Charter

3. HR Communication Plan

4. Leader's Charter

5. Leaders interview compilation.

\section{References}

[1] WILLIAM H. MACEY and BENJAMIN SCHNEIDERThe Meaning of Employee Engagement - Article first published online: 29 FEB 2008

[2] Driving Employee performance and retention through Engagement - Corporate Leadership Council

[3] Great Place to Work parameters study www.greatplacetowork.com

[4] Importance of Employee Engagement http://blog.allegiance.com/2010/08/the-importance-ofemployee-engagement/

[5] Employee Engagement notes http://www.contentwriter.in/articles/hr/employeeengagement.htm

[6] Robert J. Vance, Ph.D; SHRM Foundation's Effective Practice Guidelines. 2006. SHRM Foundation. Employee Engagement and Commitment: A guide to understanding, measuring and increasing engagement in your organization.

[7] Jamie A. Gruman and Alan M. Saks, 'Performance Management and Employee Engagement', 'Human Resource Management Review', Vol. 21, No. 2, 2011, pp. 123-136.

[8] J. K. Harter, F. L. Schmidt and E. A. Killham, 'Employee Engagement, Satisfaction, and Business-Unit-Level Outcomes: A Meta-Analysis', (Report), The Gallup Organisation, Omaha, NE, July 2003, 54pp.

[9] Nancy R. Lockwood, 'Leveraging Employee Engagement for Competitive Advantage: HR's Strategic Role', (Report), 2007, 11pp.

[10] William H. Macey and Benjamin Schneider, 'The Meaning of Employee Engagement', 'Industrial and Organisational Psychology', Vol. 1, 2008, pp. 3-30, (Article) 